\title{
Imaging of Neurovascular Compression Syndromes: Trigeminal Neuralgia, Hemifacial Spasm, Vestibular Paroxysmia, and Glossopharyngeal Neuralgia
}

\author{
(D). Haller, (D). Etienne, (DE. Kövari, (D)A.D. Varoquaux, (D). Urbach, and (D). Becker
}

\begin{abstract}
SUMMARY: Neurovascular compression syndromes are usually caused by arteries that directly contact the cisternal portion of a cranial nerve. Not all cases of neurovascular contact are clinically symptomatic. The transition zone between the central and peripheral myelin is the most vulnerable region for symptomatic neurovascular compression syndromes. Trigeminal neuralgia (cranial nerve V) has an incidence of 4-20/100,000, a transition zone of $4 \mathrm{~mm}$, with symptomatic neurovascular compression typically proximal. Hemifacial spasm (cranial nerve VII) has an incidence of 1/100,000, a transition zone of $2.5 \mathrm{~mm}$, with symptomatic neurovascular compression typically proximal. Vestibular paroxysmia (cranial nerve VIII) has an unknown incidence, a transition zone of $11 \mathrm{~mm}$, with symptomatic neurovascular compression typically at the internal auditory canal. Glossopharyngeal neuralgia (cranial nerve IX) has an incidence of $0.5 / 100,000$, a transition zone of $1.5 \mathrm{~mm}$, with symptomatic neurovascular compression typically proximal. The transition zone overlaps the root entry zone close to the brain stem in cranial nerves V, VII, and IX, yet it is more distal and does not overlap the root entry zone in cranial nerve VIII. Although symptomatic neurovascular compression syndromes may also occur if the neurovascular contact is outside the transition zone, symptomatic neurovascular compression syndromes are more common if the neurovascular contact occurs at the transition zone or central myelin section, in particular when associated with nerve displacement and atrophy.
\end{abstract}

ABBREVIATIONS: AICA = anterior inferior cerebellar artery; $\mathrm{CN}=$ cranial nerve; $\mathrm{GN}=$ glossopharyngeal neuralgia; $\mathrm{HFS}=$ hemifacial spasm; $\mathrm{NVC}=$ neurovascular compression; NVCS = neurovascular compression syndrome; REZ = root entry/exit zone; $\mathrm{TN}=$ trigeminal neuralgia; $\mathrm{TZ}$ = transition zone

N eurovascular compression syndrome (NVCS) is defined as a direct contact with mechanical irritation of cranial nerves (CNs) by blood vessels. ${ }^{1-5}$ The most common neurovascular compression syndromes are trigeminal neuralgia (TN; compression of $\mathrm{CN}$ V), hemifacial spasm (HFS; CN VII), vestibulocochlear neuralgia (CN VIII), and glossopharyngeal neuralgia (GN; $\mathrm{CN}$ IX). Because neurovascular contacts are frequent imaging findings in asymptomatic patients, several factors will determine whether a neurovascular contact may become symptomatic. First, arteries are more likely to cause symptomatic NVCS than veins,

From the Faculty of Medicine (S.H.), University of Geneva, Geneva, Switzerland; Centre de Diagnostique Radiologique de Carouge (S.H.), Carouge, Switzerland; Departments of Surgical Sciences and Radiology (S.H.), Uppsala University, Uppsala, Sweden; Department of Neuroradiology (S.H., H.U.), University Hospital Freiburg, Germany; Departments of Radiology (L.E., M.B.) and Psychiatry (E.K.), Geneva University Hospitals, Geneva, Switzerland; and Department of Radiology (A.D.V.), University Hospital La Timone, Marseille, France.

Please address correspondence to Sven Haller, MD, MSc, Affidea Centre de Diagnostique Radiologique de Carouge, Clos de la Fonderie 1, 1227 Carouge, Switzerland; e-mail: sven.haller@me.com

- Indicates open access to non-subscribers at www.ajnr.org

$\checkmark$ Indicates article with supplemental on-line video.

http://dx.doi.org/10.3174/ajnr.A4683 presumably due to the higher pressure and pulsatility. ${ }^{5,6}$ Second, the anatomic location of the neurovascular contact can also be a relevant factor.

Cranial nerves are surrounded by a myelin sheath, which provides insulating and metabolic support for the axon. Oligodendrocytes form the myelin in the central nervous system, whereas Schwann cells form the myelin in the peripheral nervous system. The transition zone (TZ) between central and peripheral myelin ${ }^{7}$ is an anatomic area with increased mechanical vulnerability, which is of particular interest in the context of symptomatic NVCS. $^{8}$ Skinner ${ }^{9}$ already demonstrated in 1931 that the length and location of the TZ varies between cranial nerves, with CN VIII having a long and distal TZ in comparison with CNs V, VII, and IX. The term "root entry/exit zone" (REZ) is often used in the context of NVCS. ${ }^{10}$ In some publications, the term "REZ" is used as a synonym for TZ, whereas in other publications, the term "REZ" is used to define the portion of the nerve that includes the $\mathrm{TZ}$, the central myelin root portion, and the adjacent brain stem surface $^{11}$; the 2 terms should, therefore, not be used interchangeably. ${ }^{8}$ The $\mathrm{TZ}$ appears to be the more relevant and vulnerable anatomic structure, and it is not always located in the same position as the REZ. For example, in the vestibulocochlear nerve (CN 

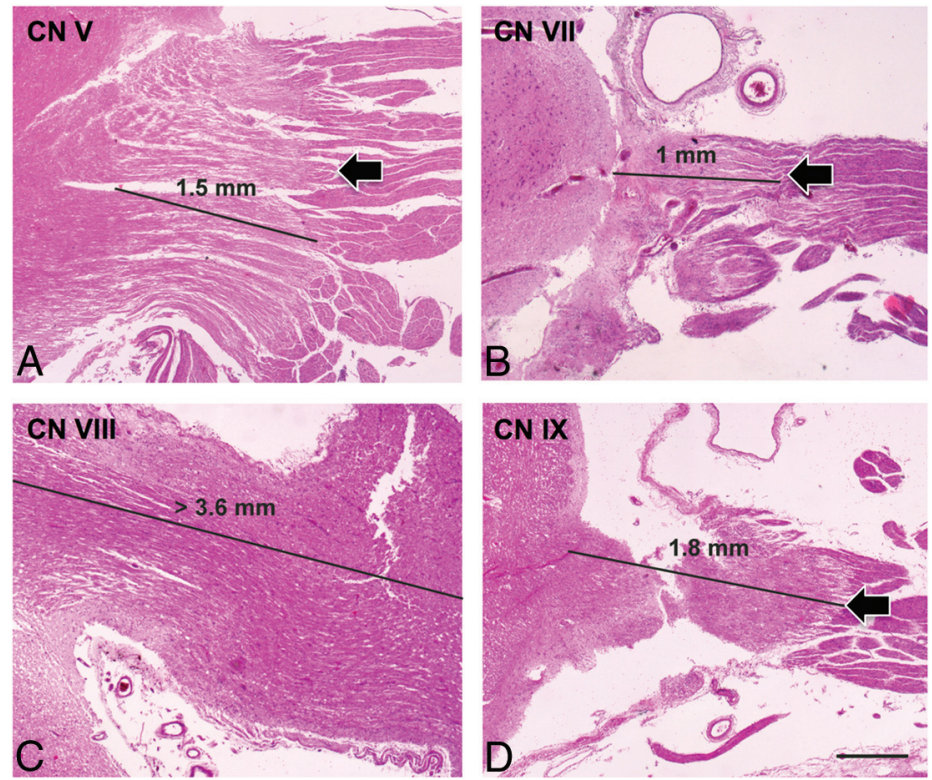

FIG 1. Histologic images of the transition zone of the trigeminal ( $C N \vee, A)$, facial ( $C N$ VII, B), vestibulocochlear (CN VIII, C), and glossopharyngeal (CN IX,D) nerves. Note the very distal TZ of $\mathrm{CN}$ VIII, which is beyond the field that can be analyzed with the current methodology compared with CNs V, VII, and IX (hematoxylin-eosin, scale bar on $D=0.5 \mathrm{~mm}$ ).

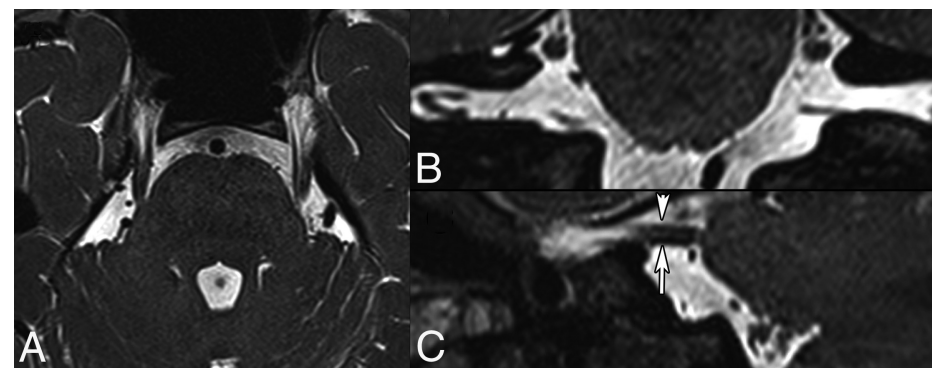

FIG 2. Normal anatomy of the cisternal segment of $C N \vee$ obtained at $3 T$. Axial 0.6-mm thinsection $(A)$, coronal $(B)$, and sagittal $(C) 2 D$ reconstructions (same thickness) from a 3D T2weighted balanced steady-state free precession sequence. Note that multiple individual nerve fibers can be identified in both cisternal CN Vs. The short arrow in C points to the motor root of the left $\mathrm{CN} V$, while the long arrow points to the sensory root.

VIII), the TZ is clearly distal to the REZ. In the current article, we, therefore, focus on the TZ.

Exact anatomic knowledge of the position and morphology of the $\mathrm{TZ}$ is of fundamental importance for the interpretation of neuroimaging findings in suspected NVCS (Fig 1). This review highlights current evidence regarding the TZ and implications for imaging. We also provide illustrative cases of normal anatomy and histologic sections from postmortem specimens for the understanding of the etiology of NVCS, as well as surgically proven cases of NVCS involving CNs V, VII, VIII, and IX.

\section{Imaging Recommendations}

The combination of high-resolution 3D T2-weighted imaging with 3D time-of-flight angiography and 3D T1-weighted gadolinium-enhanced sequences is considered the standard of reference for the detection of neurovascular compression (NVC). ${ }^{12-16}$ This combination can successfully guide neurosurgical treatment and may predict treatment response. ${ }^{17-19}$ A variety of high-resolution $3 \mathrm{D}$ heavily T2-weighted sequences is currently available, includ- ing CISS; FIESTA; balanced steady-state free precession; driven equilibrium and radiofrequency reset pulse; and sampling perfection with application-optimized contrasts by using different flip angle evolution (SPACE sequence; Siemens, Erlangen, Germany), providing accurate visualization of the cisternal portion of the involved CN. Multiplanar oblique reconstructions and fusion of 3D T2-weighted sequences with corresponding TOF images or 3D T1weighted gadolinium-enhanced images are very useful in the preoperative context. More recently, diffusion tensor imaging with tractography has been increasingly used, mainly in trigeminal neuralgia. ${ }^{15,20,21}$

\section{Trigeminal Nerve (CN V)}

Anatomic Considerations. $\mathrm{CN} \mathrm{V}$ is a mixed nerve responsible for the sensory innervation of the face and motor functions of the masticatory muscles and tensor veli palatine muscle. It has 3 main branches: the ophthalmic (V1), the maxillary (V2), and the mandibular (V3) nerve. These 3 branches join the Gasserian ganglion in the Meckel cave. The Gasserian ganglion transmits the sensory information to the brain stem via the cisternal portion (Figs 2 and 3). NVCS occurs at the cisternal portion. The cisternal portion measures between 8 and $15 \mathrm{~mm}$ in length, and the zone with central myelin (distance from brain stem to the TZ) is shorter on the medial side of the nerve $(1.13 \mathrm{~mm})$ than on its lateral side $(2.47 \mathrm{~mm}){ }^{8} \mathrm{~A}$ histologic study in fresh cadavers has shown that the TZ measures about $2 \mathrm{~mm}$ in length and the most distal part of the TZ is at $4.19 \pm 0.81 \mathrm{~mm}$ away from the brain stem (Fig 1 and Table 1$).{ }^{11}$ The reported volume of the normal cisternal CN V measured on 3T MR imaging in vivo is $77.4-78 \mathrm{~mm}^{3}$ in men and $66.1-66.4$ $\mathrm{mm}^{3}$ in women, with no statistically significant difference found between the left and right. ${ }^{22}$ With current MR imaging technology, it is also possible to visualize 1 (51.2\%), 2 (37.5\%) or even 3 (11.2\%) small motor roots that typically emerge from the pons anterosuperomedially to the entry point of the large sensory root (Fig 2). ${ }^{13}$

Trigeminal Neuralgia. The most common cause of trigeminal neuralgia is NVCS; however, other etiologies, such as neoplastic, inflammatory, and infectious conditions or trauma, may exist as well. Patients with "classic" or "idiopathic" TN have recurrent episodes of stabbing pain in the territory of V1 or V2. The pain is triggered by mild stimulation of a small area of the face ("trigger zone”) by everyday activities, such as brushing teeth, shaving, eat- 


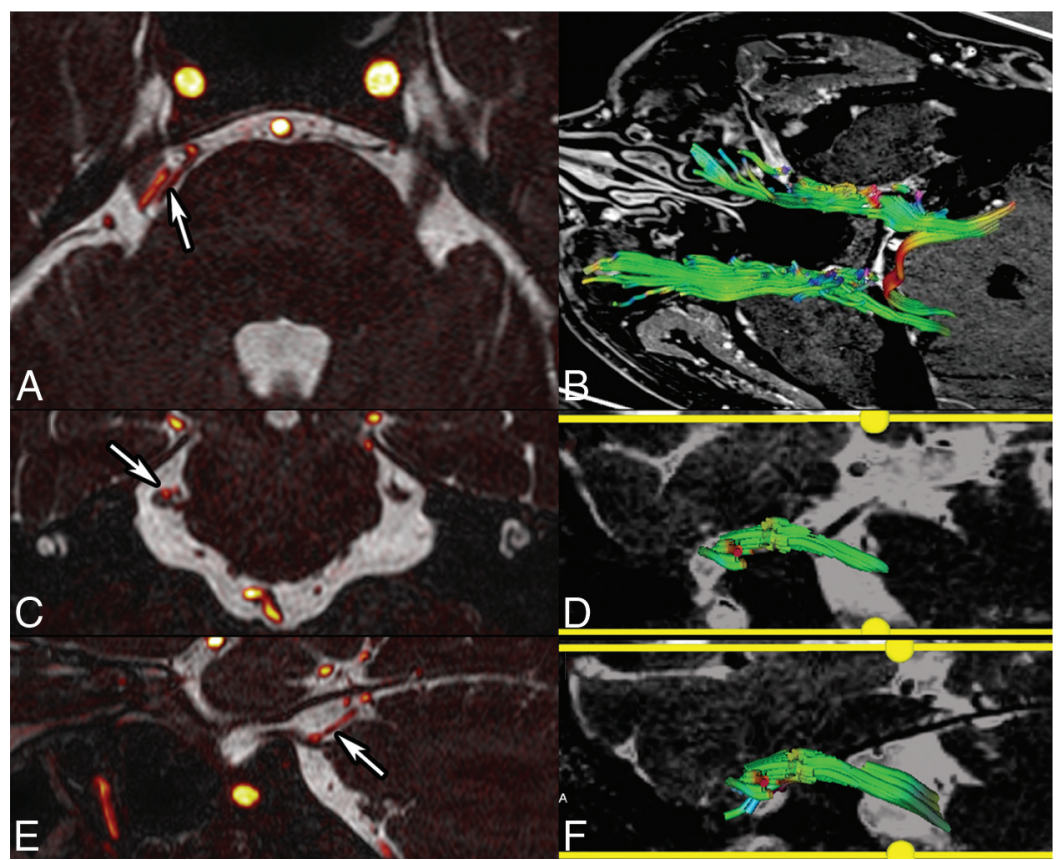

FIG 3. NVCS in a 55-year-old woman with right TN. Fusion of CISS $(0.6-\mathrm{mm}$ sections) and TOF angiography sequences ( $A$, axial; $C$, coronal; $E$, sagittal) show contact between the duplicated superior cerebellar artery and the superior portion of the cisternal CN V (arrows). Tractography reconstruction from $D T I$ ( $B$, superior view; $D$, right $C N V$; $F$, left $C N V$ ) shows a slightly diminished number of fibers on the right, as opposed to the left. Fiber color-coding is the following: anteroposterior $=$ green; left-right $=$ red; craniocaudal $=$ blue. Fractional anisotropy measurements show diminished values on the right.

Table 1: Cisternal length and transition zone of cranial nerves V, VII, VIII, and IX ${ }^{\mathrm{a}}$

\begin{tabular}{|c|c|c|}
\hline & Cisternal Length & TZ \\
\hline \multirow[t]{3}{*}{ CN V: trigeminal nerve } & $8-15 \mathrm{~mm}^{\mathrm{b}}$ & $1.13 \mathrm{~mm}$ (medial) ${ }^{\mathrm{b}}$ \\
\hline & $13.11 \pm 1.12 \mathrm{~mm}(\text { range, } 11.9-15.2 \mathrm{~mm})^{c}$ & $2.47 \mathrm{~mm}$ (lateral) $^{\mathrm{b}}$ \\
\hline & Motor root, $2-20 \mathrm{~mm}^{\mathrm{d}}$ & $4.19 \pm 0.81 \mathrm{~mm}^{\mathrm{c}}$ \\
\hline \multirow[t]{2}{*}{ CN VII: facial nerve } & $17.93 \pm 2.29 \mathrm{~mm}(\text { range, } 14.8-20.9 \mathrm{~mm})^{\mathrm{c}}$ & $2.86 \pm 1.19 \mathrm{~mm}^{\mathrm{c}}$ \\
\hline & $\begin{array}{l}9.9 \pm 3.03 \mathrm{~mm} \text { (range, } 4.78-20.13 \mathrm{~mm}) \\
\text { lateral side }\end{array}$ & $1.9 \pm 1.14^{\mathrm{e}}$ \\
\hline CN VIII: vestibulocochlear nerve & $16.48 \pm 1.78 \mathrm{~mm}(\text { range, } 14.2-19.2 \mathrm{~mm})^{\mathrm{f}}$ & $11.50 \pm 1.56 \mathrm{~mm}^{f}$ \\
\hline CN IX: glossopharyngeal nerve & $16.36 \pm 2.53 \mathrm{~mm}(\text { range, } 14.2-19.9 \mathrm{~mm})^{c}$ & $1.51 \pm 0.39 \mathrm{~mm}^{\mathrm{c}}$ \\
\hline
\end{tabular}

${ }^{a}$ Values are mean \pm standard deviation in $\mathrm{mm}$ (and range in $\mathrm{mm}$ ).

b Peker et al. ${ }^{8}$

"Guclu et al."

${ }^{d}$ Yousry et al. ${ }^{13}$

e Tomii et al. . $^{36}$

${ }^{f}$ Guclu et al. ${ }^{53}$

Table 2: Incidence of symptomatic neurovascular compression syndromes

\begin{tabular}{llc}
\hline & \multicolumn{1}{c}{ NVCS } & Incidence \\
\hline CN V & Trigeminal neuralgia & $4.3 / 100,000^{\mathrm{a}}$ \\
& & $4-20 / 100,000^{\mathrm{b}}$ \\
CN VII & Hemifacial spasm & $0.77 / 100,000^{\mathrm{c}}$ \\
CN VIII & Vestibular paroxysmia & - \\
CN IX & Glossopharyngeal neuralgia & $0.062 / 100,000^{\mathrm{d}}$ \\
& & $0.2-0.7 / 100,000^{\mathrm{b}}$ \\
\hline
\end{tabular}

\footnotetext{
${ }^{a}$ Katusic et al. ${ }^{24}$

${ }^{\mathrm{b}}$ Manzoni and Torelli. ${ }^{25}$

c Auger and Whisnant. ${ }^{49}$

${ }^{\mathrm{d}}$ Spurling and Grantham. ${ }^{58}$
}

ing, or applying makeup. Typically, no neurologic deficits are clinically evident. Between attacks, most patients are usually painfree. However, the longer the TN lasts, the more intense the pain becomes and the more frequent the attacks are. When patients present a steady component or mild sensory loss between the attacks, the term "atypical TN" is used. ${ }^{23}$ The overall prevalence of $\mathrm{TN}$ is estimated to be in the range of $4-20 / 100,000,,^{24,25}$ and women are affected more often than men (Table 2). ${ }^{25,26}$ Although rare, pediatric cases have been described as well. ${ }^{23}$

NVCS of CN V is usually caused by a neighboring elongated superior cerebellar artery coming from above (Fig 3 and On-line Video) or by an anterior inferior cerebellar artery (AICA) coming from below, ${ }^{11}$ with the superior cerebellar artery being more common (88\% alone or in association) than the AICA $(\leq 25 \%) .^{5}$ Both the superior cerebellar artery and AICA usually compress the nerve in its superomedial portion $(60 \%)$ (Fig 3). ${ }^{5}$ Less often, CN V is compressed by the basilar and vertebral arteries, ${ }^{15,16}$ by a saccular aneurysm, a persistent trigeminal artery, an arteriovenous malformation, ${ }^{27,28}$ or a petrous vein (Figs 4 and 5). A small cerebellopontine angle cistern appears to predispose to NVCS. ${ }^{29}$ Histologically, in patients with $\mathrm{TN}$, the cisternal CN V shows focal demyelination in the region of vascular compression. $^{8,23,30,31} \mathrm{TN}$ has been reported to be more frequent in proximal $(<3 \mathrm{~mm})$ than in distal NVC. ${ }^{32}$ According to Peker et $\mathrm{al}^{8}{ }^{8}$ the $\mathrm{TZ}$ of $\mathrm{CN} \mathrm{V}$ is $<2.5 \mathrm{~mm}$ away from the brain stem, while according to Guclu et al, ${ }^{11}$ the $\mathrm{TZ}$ is at approximately $4.19 \pm 0.81 \mathrm{~mm}$ away. Therefore, the proposed practical cutoff of $3 \mathrm{~mm}$ for the location of the TZ with respect to the nerve entry/exit is a reasonable compromise. It is certainly an oversimplification to assume that NVCS can occur only at the TZ because nerve compression has been described in the proximal cisternal, midcisternal, and juxtapetrous nerve segments. ${ }^{17}$ Furthermore, in a series of 579 patients with TN, ${ }^{5} \mathrm{NVCS}$ was found to be equally frequent in the proximal and in the mid-third cisternal $\mathrm{CN}$, while it was clearly less frequent in the Meckel cave. ${ }^{5}$

In most patients with classic $\mathrm{TN}$, surgical decompression of the $\mathrm{CN} V$ root produces immediate intraoperative improvement in nerve conduction and rapid symptom relief (Fig 4). This phenomenon is thought to reflect the reversal of a compression-induced conduction block in larger myelinated fibers outside the region of demyelination. ${ }^{23}$ Immediate postoperative pain relief is between $87 \%$ and $98 \%$. Approximately $80 \%$ of patients with microvascular decompression are symptom-free 1 year after the procedure; however, 8-10 years later, this percentage decreases to $58 \%-68 \% .^{33,34}$ Immediate postoperative remission is an independent predictive factor for good long-term outcome after mi- 


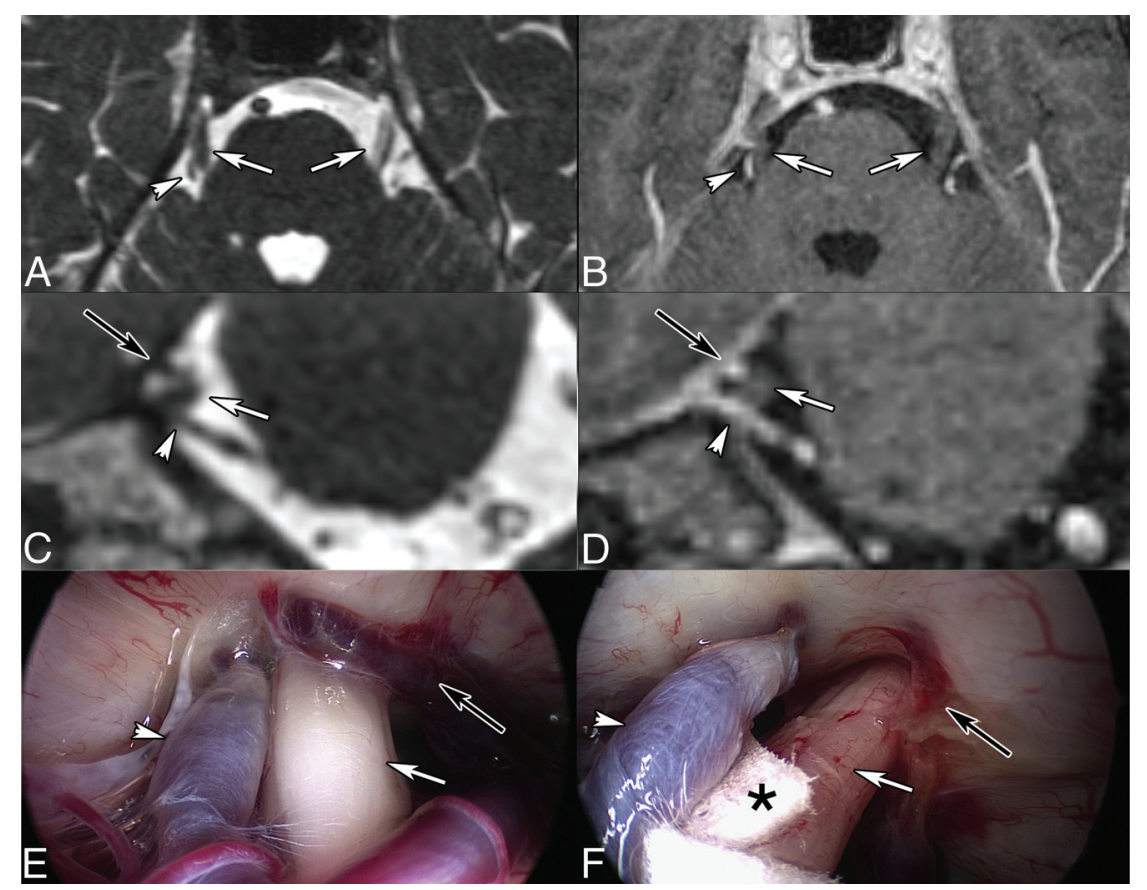

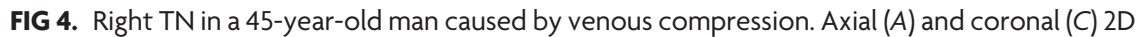
reconstruction from CISS $(0.7-\mathrm{mm}$ thin sections). Contrast-enhanced 3D T1-weighted reconstructed images $(0.9 \mathrm{~mm})$ in the axial $(B)$ and coronal $(D)$ planes. Intraoperative views before $(E)$ and after $(F)$ the operation. MR imaging shows bifocal CN V (white arrows) compression by the Dandy vein (white short arrows) and by a transverse pontine vein (black arrows), respectively. Teflon (Dupont, Wilmington, Delaware) (asterisk, F) was interposed between CN V (white arrow, $F$ ) and the Dandy vein (white arrowhead, F). The transverse pontine vein was coagulated (black arrow, F). Intraoperative images are courtesy of Dr Arnaud Deveze, MD, Department of Ear, Nose and Throat Surgery, University Hospital, Hôpital Nord, Marseille, France.

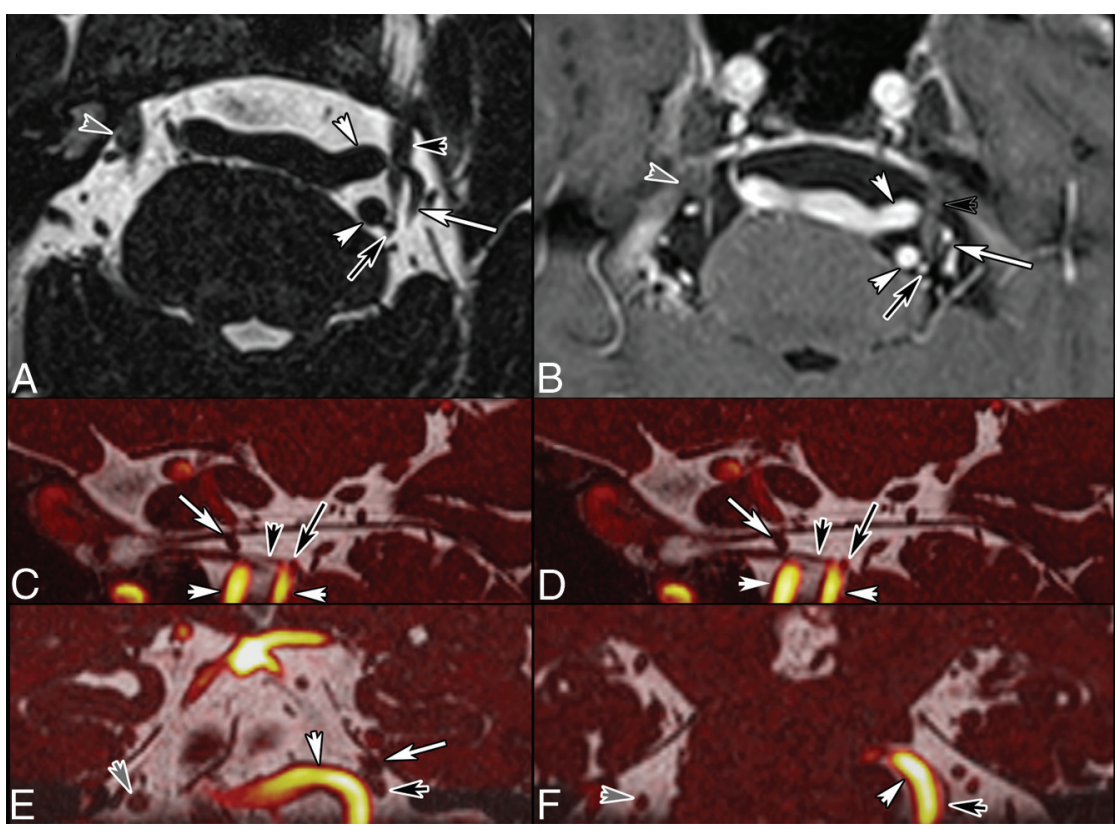

FIG 5. NVCS in a 70-year-old man with left TN. Axial T2-weighted image ( $A, 0.5 \mathrm{~mm})$. Contrastenhanced T1-weighted image $(B, 0.5 \mathrm{~mm})$. Fusion of 3D T2 and TOF angiography sequences ( $C$ and $D$, sagittal; $E$ and $F$, coronal sections). Note contact between the tortuous vertebral arteries (white arrowheads), the left AICA (black arrows), the superior cerebellar artery (white arrows), and the cisternal left CN V (black arrowheads). Note that the TZ of CN V is thinned, while the more distal portion of CN V close to the Meckel cave has a normal rounded shape. Gray arrowhead points to the right $\mathrm{CN} \mathrm{V}$. crovascular decompression. ${ }^{34}$ Before $^{3}$ considering microvascular decompression, patients usually undergo pharmacologic treatment with carbamazepine, oxcarbazepine, or, in selected cases, baclofen, gabapentin, and other anticonvulsants. Further treatment options in TN include stereotactic radiosurgery (also called "gamma knife"), which is increasingly performed, especially in elderly patients.

Neurovascular contacts due to vessel juxtaposition along CN V also occur in a non-negligible percentage of asymptomatic subjects $(31.9 \%$ of control subjects and $48.9 \%$ on the contralateral asymptomatic side in patients with TN). ${ }^{35}$ In a combined MR imaging and specimen study, the superior cerebellar artery and AICA had contact with the sensory CN V root in $45.5 \%$ of all MR imaging examinations and in $42.9 \%$ of specimens. ${ }^{13}$ Asymptomatic contact is more common more distal to the brain stem $(3.85 \pm 2.69 \mathrm{~mm})$, compared with symptomatic NVC, which is typically proximal $(0.94 \pm 1.27 \mathrm{~mm}) .{ }^{32}$ A cutoff value of $3 \mathrm{~mm}$ from the brain stem has been proposed because TN symptoms occur in $83.1 \%(103 / 124)$ of cases with neurovascular contact at a distance of $<3 \mathrm{~mm}$, but only in $19.6 \%$ (9/46) of patients with a distance of $>3 \mathrm{~mm} .^{32}$

Similar results were found by other authors: Neurovascular contact occurred in the proximal part (REZ in this study) in $76 \%$ of symptomatic and $17 \%$ of asymptomatic nerves. ${ }^{36}$ These observations indicate that proximal NVCs are more likely symptomatic than distal NVCs, yet the pure presence or absence of an NVC is insufficient to accurately predict symptomatic NVCS. Consequently, additional parameters may determine whether a neurovascular contact is symptomatic. Tash et $\mathrm{al}^{37}$ assessed 85 asymptomatic patients and found $30 \%$ of $170 \mathrm{CN}$ Vs with a neurovascular contact in the REZ, but only $2 \%$ of these asymptomatic cases had a deformity of the nerve. Correspondingly, the presence of nerve displacement by the vessel or focal atrophy was observed more commonly in symptomatic (52\%) compared with asymptomatic (9\%) nerves. $^{36}$

Atrophy of $\mathrm{CN} \mathrm{V}$ in patients with classic TN has been observed intra- 
operatively and at MR imaging (Fig 4). ${ }^{29,38-41}$ Erbay et $\mathrm{al}^{39}$ found that the nerve diameter and cross-sectional area were $20 \%$ and $28 \%$ smaller on the symptomatic side compared with the asymptomatic side. Horínek et $\mathrm{al}^{40}$ found that the volume of the affected nerve was, on average, $28 \%$ smaller than that of the unaffected nerve; however, only 7 of the 18 patients with TN were diagnosed

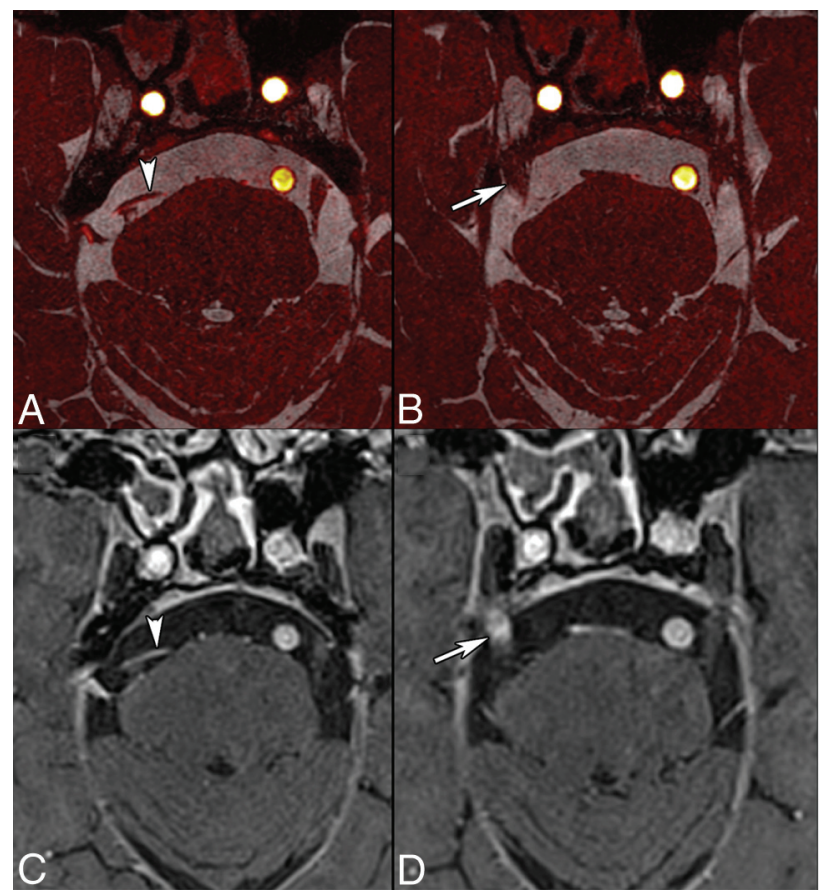

FIG 6. TN in an 81-year-old man treated with stereotactic radiosurgery. Axial images $(0.5 \mathrm{~mm})$ obtained by fusion of CISS and TOF angiography sequences $(A$ and $B$ ) and contrast-enhanced 3D T1weighted volumetric interpolated brain examination ( $C$ and $D, 0.6$ $\mathrm{mm}$ ) show NVCS caused by the superior cerebellar artery (arrowheads). There is contrast enhancement of the right $\mathrm{CN} V$ at the stereotactic radiosurgery site $(\operatorname{arrow}, D)$. Contrast enhancement on follow-up examinations disappeared gradually. with nerve atrophy on the basis of MR imaging volumetry. Although CN V atrophy can be observed in TN, the low sensitivity of this finding does not warrant its routine use for the diagnosis of trigeminal NVCS. Nevertheless, according to Antonini et al, in $2014,{ }^{36}$ nerve atrophy and displacement are highly specific (97\%) signs with good negative $(82 \%-87 \%)$ and positive $(81 \%-86 \%)$ predictive values. In summary, anatomic abnormalities such as deformity and atrophy of the cisternal CN V and a small cerebellopontine angle cistern are more frequent in symptomatic NVCS and — whenever present—-should be used as additional diagnostic signs.

DTI in severe TN may reveal a loss of anisotropy due to tissue damage associated with demyelination. ${ }^{20,39,42,43}$ A reduction of fractional anisotropy, increase in radial diffusivity and apparent diffusion coefficient, and a trend toward increased mean diffusivity can be observed in NVCS. Furthermore, reversibility of an abnormally low fractional anisotropy has been reported after successful microvascular decompression. ${ }^{20}$ DTI metrics also appear to correlate with clinical parameters, such as disease duration and the visual analog scale of pain. ${ }^{42}$ Therefore, it has been suggested that correlation between fractional anisotropy reduction and the visual analog scale suggests fractional anisotropy as a potential objective MR imaging biomarker to correlate with clinical severity. ${ }^{42}$ However, these observations have not been confirmed by other authors and, therefore, require further investigation. ${ }^{44}$

MR imaging can also be used to assess padding or other morphologic and functional changes after microvascular decompression ${ }^{45}$ or stereotactic radiosurgery (gamma knife) for TN. After stereotactic radiosurgery, the affected nerve may show focal contrast enhancement (Fig 6), and gradual decrease of nerve volume occurs with time. Park et $\mathrm{al}^{29}$ found $\mathrm{CN} \mathrm{V}$ atrophy of the affected side in $96 \%$ of patients with TN treated by stereotactic radiosurgery, with a mean reduction in $\mathrm{CN} \mathrm{V}$ volume of $39 \%$.

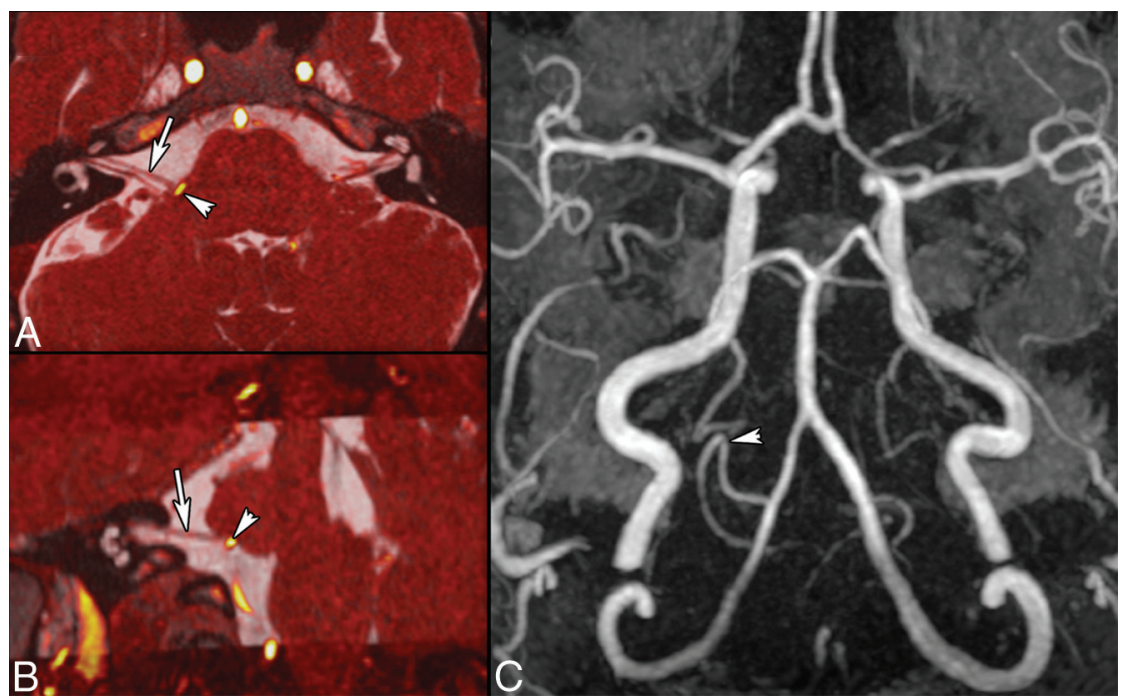

FIG 7. HFS caused by a posterior inferior cerebellar artery (PICA) loop in a 54-year-old man. Axial oblique $(A)$ and coronal oblique $(B)$ reformatted images obtained by fusion of CISS $(0.6 \mathrm{~mm})$ and TOF angiography sequences show NVC of CN VII (arrows, $A$ and $B$ ) by the PICA at the presumed TZ (arrowhead). 3D MIP reconstruction of the TOF sequence $(C)$ shows a PICA loop on the right, responsible for HFS. Findings were confirmed surgically.

\section{Facial Nerve (CN VII)}

Anatomy. CN VII is a mixed nerve, which essentially controls the muscles of facial expression, transmits taste sensations from the anterior two-thirds of the tongue, and supplies parasympathetic fibers to the nasal mucosa, submandibular, sublingual, and lacrimal glands. The motor component is of particular relevance in the context of the current review. CN VII exits the brain stem as a single entity forming the cisternal segment (Fig 1). Analogous to CN V, most cases of NVCS also occur in the cisternal segment. According to one study, ${ }^{11}$ the length of the cisternal segment was $17.93 \pm 2.29 \mathrm{~mm}$ (range, 14.8-20.9 $\mathrm{mm})$. In another study, ${ }^{46}$ the $\mathrm{TZ}$ was described at $1.9 \mathrm{~mm}$ from the nerve entry/exit into the brain stem, which is about one-tenth of its cisternal 


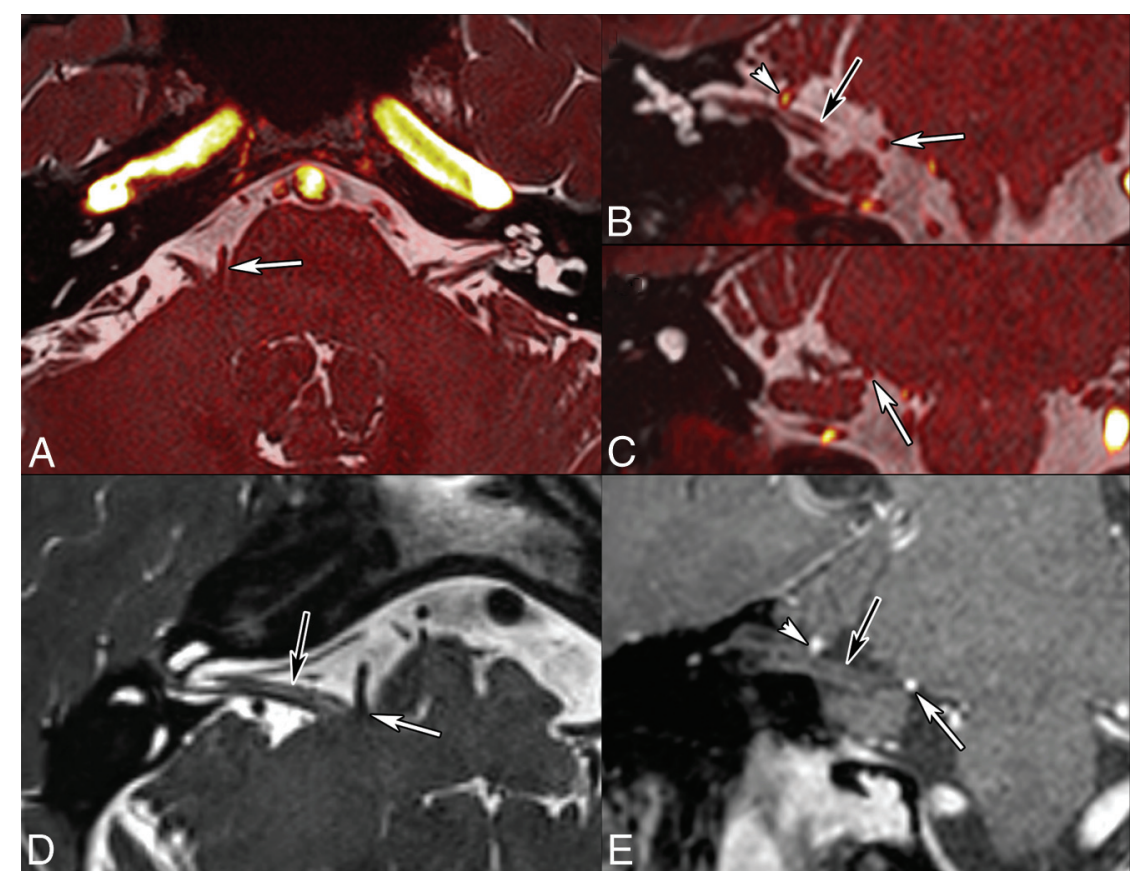

FIG 8. Right HFS caused by an AICA loop in a 60-year-old man. Fusion of 3D T2 and TOF angiography sequences (0.6-mm thin sections; $A$, axial; $B$ and $C$, coronal sections). Axial oblique reformatted T2-weighted image along the cisternal CN VII (D). Coronal oblique reformatted contrastenhanced T1-weighted image $(E)$. Note contact between an AICA loop and the presumed TZ of CN VII (white arrows), which is slightly indented. There is a second contact between the AICA and the more distal CN VII (arrowheads). Black arrows point to CN VII. NVCS due to the AICA loop impinging on the TZ was confirmed surgically. After the operation, symptoms disappeared.

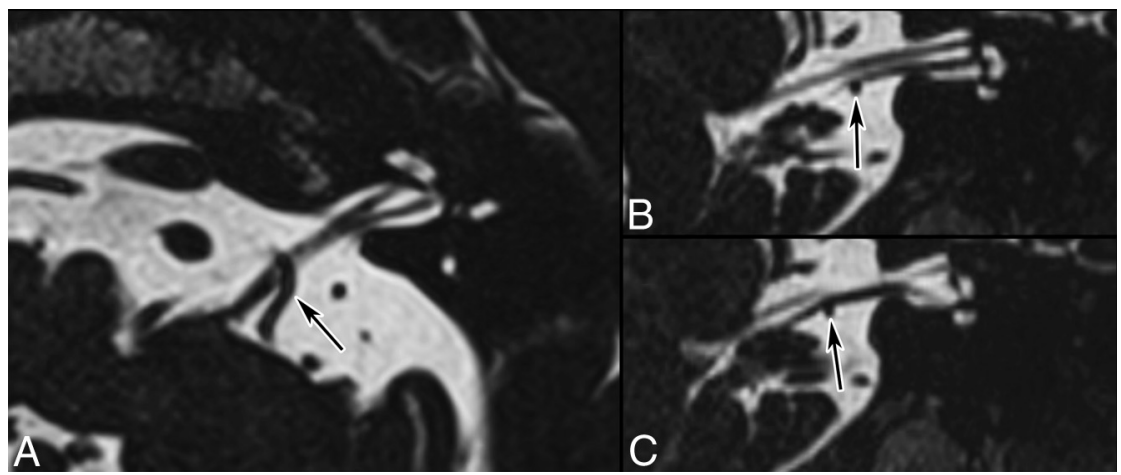

FIG 9. NVC in a 70-year-old man with tinnitus and vertigo. A, Axial oblique reformatted T2weighted image $(0.5 \mathrm{~mm})$. Coronal oblique T2-weighted images $(0.5 \mathrm{~mm} ; B$, anterior section; $C$, posterior section). Note the tortuous AICA (arrows) displacing and indenting the cochlear nerve $(B)$ and the vestibular nerve $(C)$. Brain and temporal bone MR imaging and high-resolution temporal bone CT findings were otherwise normal.

length. ${ }^{47}$ Another study reported that the most distal part of the $\mathrm{TZ}$ is $2.86 \mathrm{~mm}$ away from the brain stem. ${ }^{11}$ By interpolating these data, we can estimate the length of the $\mathrm{TZ}$ to be about $0.96 \mathrm{~mm}$ (range, 2.86-1.9 mm). Similar to CN V, the medial portion of the TZ is also shorter than the lateral portion. ${ }^{46,47}$

Hemifacial Spasm. Hemifacial spasm is characterized by unilateral, intermittent contractions of the muscles of facial expression, typically beginning in the orbicularis oculi and spreading to the other muscles. ${ }^{48}$ Primary HFS is triggered by NVC, whereas secondary HFS comprises all other causes of CN VII damage. HFS has an incidence of $0.77 / 10,000 .{ }^{49}$ The AICA (43\%) is the most common vessel causing NVC (Figs 7 and 8), followed by the pos- terior inferior cerebellar artery (31\%) and vertebral artery $(23 \%) .{ }^{6}$ NVCS can occur either at the REZ (10\%-96\% depending on study), ${ }^{50,51}$ adjacent cisternal segment (up to $64 \%$ ), ${ }^{6} \mathrm{TZ}(22 \%)$, or other cisternal portions $(3 \%){ }^{6}$ According to Dou et al, ${ }^{52}$ attrition of the neurovascular interface yields action potentials from the demyelinated facial nerves and therefore causes HFS symptoms. As shown by Sindou et $a{ }^{51}$ microvascular decompression is highly effective in HFS and symptoms disappear after an operation in $90 \%-95 \%$ of cases; however, recurrence is seen in up to $25 \%$ of patients. In the long term, $75 \%-85 \%$ of patients remain symptom-free.

\section{Vestibulocochlear Nerve (CN VIII)}

Anatomic Considerations. CN VIII is a sensory nerve carrying information from the spiral auditory organ (cochlear nerve) and the labyrinth (vestibular nerve) to the brain stem. It has a long cisternal segment, which extends from the brain stem to the internal acoustic meatus (total distance $=14.2-19.2$ $\mathrm{mm}) .^{53}$ The distance of the most distal part of the TZ from the brain stem has been measured at 9.28-13.84 mm (Fig 1). Most acoustic schwannomas originate from the internal auditory canal or its porus area, ${ }^{47}$ which is colocalized with the TZ. Consequently, it was postulated that acoustic schwannomas might originate from the glio-Schwannian junction. ${ }^{53}$ The alternative hypothesis is that the origin of many acoustic schwannomas is the ganglion of Scarpa, which is also colocalized in this region. ${ }^{54}$

NVC of CN VIII (Vestibular Paroxysmia). In contrast to the clearly established NVCS of CN V and VII, NVCS of CN VIII is more controversial. ${ }^{55}$ The site of NVC can vary between 0.0 and $10.2 \mathrm{~mm}$ from the brain stem, and in most cases (75\%), the AICA is the compressing vessel. ${ }^{56}$ The recording of action potentials of the cochlear nerve during microvascular decompression has demonstrated that the site of NVC correlates well with clinical symptoms. ${ }^{55}$ Ryu et $\mathrm{al}^{55}$ have shown that vertigo appears to be associated with vascular compression of the rostroventral nerve (vestibular nerve), while tinnitus appears to be associated with compression of the caudal surface (cochlear nerve) of the nerve (Fig 9). In patients with both vertigo and tinnitus, the authors found compression of both the vestibular and cochlear nerves. ${ }^{55}$ 


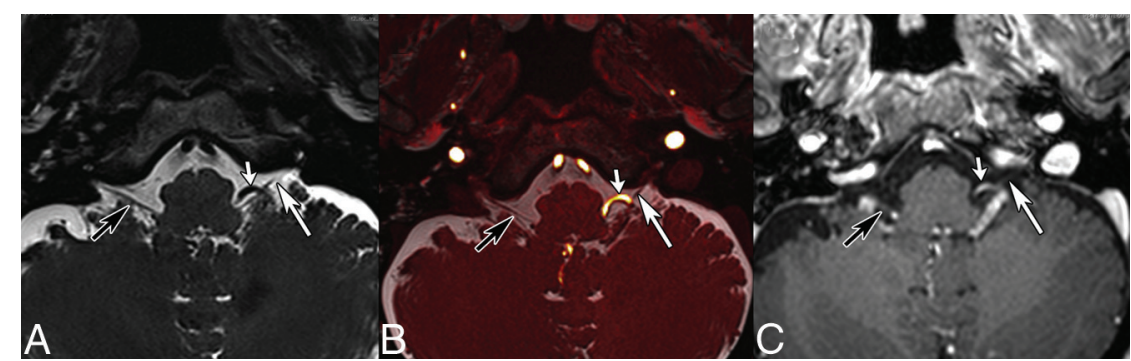

FIG 10. GN caused by a tortuous vertebral artery in a 64-year-old man. Axial T2-weighted (A), fused T2-weighted and TOF $(B)$ images, and contrast-enhanced 3D T1 gradient recalled-echo image (C) show displacement and contact between CN IX (long arrows) and a tortuous vertebral artery (short arrows). Note that in B, 2 contact points are seen, 1 proximal and 1 more distal. Black arrows point to the contralateral IX-X nerve complex. Findings were confirmed surgically. input comes from the carotid body and carotid sinuses. The motor component supplies the stylopharyngeal muscle and the secretomotor fibers of the ipsilateral parotid gland. As opposed to $\mathrm{CN} \mathrm{V}$ and VII, CN IX exits as 3-5 rootlets, which later unite to form the cisternal CN IX. The length of CN IX from the medulla oblongata to the jugular foramen varies between 14.2 and $19.9 \mathrm{~mm}$ (mean, $16.36 \pm 2.53 \mathrm{~mm}) .{ }^{11}$ The $\mathrm{TZ}$ is located at $1.51 \pm 0.39 \mathrm{~mm}^{11}$ and has a typical cone shape (Fig 1). ${ }^{9}$

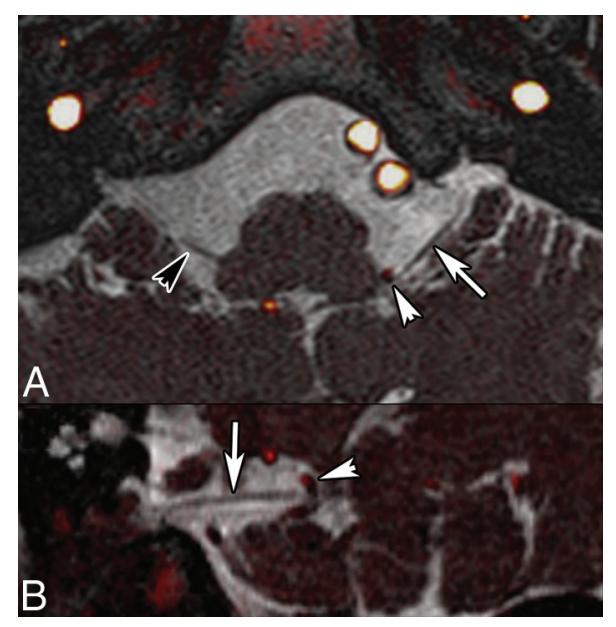

FIG 11. Left invalidating GN caused by a posterior inferior cerebellar artery (PICA) loop in an 80-year-old otherwise healthy female patient. Fusion of $3 \mathrm{D}$ T2 and TOF angiography sequences ( $A$, axial; $B$, coronal oblique) reveals displacement of CN IX (white arrows) and contact between the TZ of CN IX and the left PICA (arrowheads). Right CN IX is indicated by a black arrowhead.
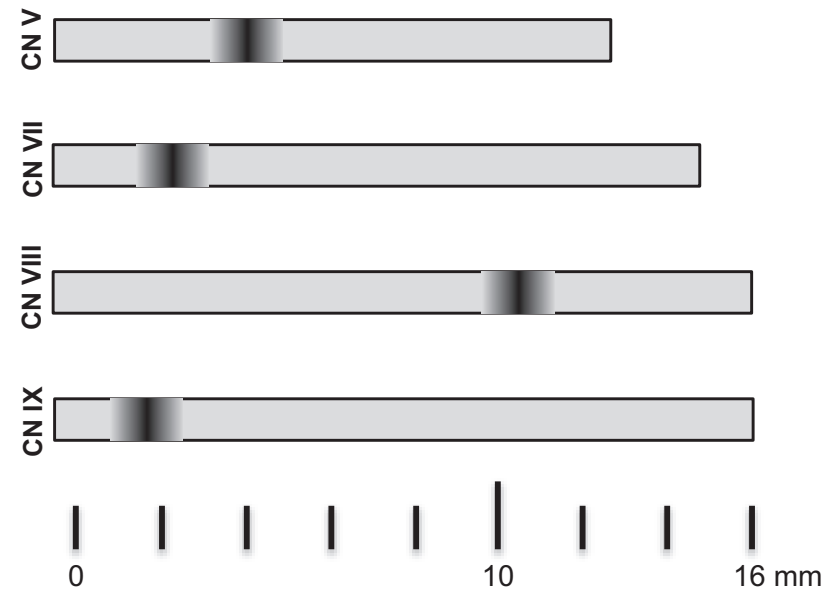

FIG 12. Schematic illustration of the cisternal length and location of the transition zone for CN V, VII, VIII, and IX.

\section{Glossopharyngeal Nerve (CN IX)}

Anatomy. CN IX is a mixed sensory, motor, and parasympathetic nerve. Sensory information comes from the posterior tongue and oropharyngeal and ear region, while chemo- and baroreceptor
Glossopharyngeal Neuralgia. Glossopharyngeal neuralgia is characterized by severe paroxysmal episodes of pain localized in the posterior tongue, tonsil, throat, or external ear canal. The pain is similar to that experienced by patients with $\mathrm{TN}$ and can be triggered by eating, swallowing, and speaking. ${ }^{57}$ Life-threatening complications due to cardiac instability, syncope, and convulsions are well-documented. The overall incidence of GN appears to be considerably lower than that of TN and is estimated at $0.2-$ 0.7 cases per 100,000 person-years ${ }^{25}$ and $0.062 / 100,000$ (Fig 7). ${ }^{58}$ However, some authors believe that the true incidence of GN may be higher due to lack of awareness of the disease and difficulties in diagnosis. In general, GN is caused by NVC, while in a minority of cases, trauma, neoplasms, infection, or an elongated styloid process (Eagle syndrome) can be identified. Because symptoms are not always straightforward, imaging is usually performed to exclude a neoplasm in the pharynx or larynx or to look for an elongated styloid process. Analogous to CN V and VII, in patients with GN caused by NVCS, MR imaging allows precise assessment of the relationship between CN IX and the conflicting artery in the supraolivary fossette (Figs 10 and 11). GN caused by NVC occurs almost exclusively (95\%) in the proximal REZ, ${ }^{59}$ which overlaps the proximal location of the $\mathrm{TZ}$ of $1.51 \pm 0.39 \mathrm{~mm} .{ }^{11}$ The posterior inferior cerebellar artery and, less frequently, the AICA are responsible for nerve compression. ${ }^{60,61}$ The low incidence of GN in comparison with CN V and CN VII is probably related to the proximal position of the $\mathrm{TZ}$ and the short central myelin portion in CN IX. ${ }^{10,11}$

\section{CONCLUSIONS}

TZ length and location vary between cranial nerves (Fig 12). While the TZ is close to the brain stem and overlaps the REZ in $\mathrm{CN}$ V, VII, and IX, it is longer, located more distally, and does not overlap the REZ in CN VIII. ${ }^{9}$ Although symptomatic NVCS can occur outside the TZ, most NVCSs are seen at the TZ. MR imaging with high-resolution heavily $\mathrm{T} 2$-weighted sequences and angiography sequences plays a major role in the identification of the compressing vessel, its precise location, and ruling out other causes of pain that may mimic NVCS. DTI with tractography is a potential biomarker in $\mathrm{TN}$.

Disclosures: Sven Haller-UNRELATED: Grants/Grants Pending: Swiss National Science Foundation, ${ }^{*}$ Comments: project on real-time fMRI neurofeedback. *Money paid to the institution. 


\section{REFERENCES}

1. Dandy WE. Concerning the cause of trigeminal neuralgia. Am J Surg 1934;24:447-55 CrossRef

2. Gardner WJ, Miklos MV. Response of trigeminal neuralgia to decompression of sensory root: discussion of cause of trigeminal neuralgia. J Am Med Assoc 1959;170:1773-76 CrossRef Medline

3. Gardner WJ. Concerning the mechanism of trigeminal neuralgia and hemifacial spasm. J Neurosurg 1962;19:947-58 CrossRef Medline

4. Jannetta PJ. Arterial compression of the trigeminal nerve at the pons in patients with trigeminal neuralgia. J Neurosurg 1967; 26(suppl):159-62 CrossRef Medline

5. Sindou M, Howeidy T, Acevedo G. Anatomical observations during microvascular decompression for idiopathic trigeminal neuralgia (with correlations between topography of pain and site of the neurovascular conflict): prospective study in a series of $\mathbf{5 7 9}$ patients. Acta Neurochir (Wien) 2002;144:1-12; discussion 12-13 CrossRef Medline

6. Campos-Benitez M, Kaufmann AM. Neurovascular compression findings in hemifacial spasm. J Neurosurg 2008;109:416-20 CrossRef Medline

7. Tarlov IM. Structure of the nerve root, I: nature of the junction between the central and the peripheral nervous system. Arch NeurPsych 1937;37:555-83 CrossRef

8. Peker S, Kurtkaya O, Uzün I, et al. Microanatomy of the central myelin-peripheral myelin transition zone of the trigeminal nerve. Neurosurgery 2006;59:354-59; discussion 354-59 CrossRef Medline

9. Skinner H. Some histologic features of the cranial nerves. Arch NeurPsych 1931;25:356-72 CrossRef

10. De Ridder D, Møller A, Verlooy J, et al. Is the root entry/exit zone important in microvascular compression syndromes? Neurosurgery 2002;51:427-33; discussion 433-34 CrossRef Medline

11. Guclu B, Sindou M, Meyronet D, et al. Cranial nerve vascular compression syndromes of the trigeminal, facial and vago-glossopharyngeal nerves: comparative anatomical study of the central myelin portion and transitional zone-correlations with incidences of corresponding hyperactive dysfunctional syndromes. Acta Neurochir (Wien) 2011;153:2365-75 CrossRef Medline

12. Leal PR, Froment JC, Sindou M. MRI sequences for detection of neurovascular conflicts in patients with trigeminal neuralgia and predictive value for characterization of the conflict (particularly degree of vascular compression) [in French]. Neurochirurgie 2010; 56:43-49 CrossRef Medline

13. Yousry I, Moriggl B, Holtmannspoetter M, et al. Detailed anatomy of the motor and sensory roots of the trigeminal nerve and their neurovascular relationships: a magnetic resonance imaging study. J Neurosurg 2004;101:427-34 CrossRef Medline

14. Leal PR, Hermier M, Souza MA, et al. Visualization of vascular compression of the trigeminal nerve with high-resolution 3T MRI: a prospective study comparing preoperative imaging analysis to surgical findings in $\mathbf{4 0}$ consecutive patients who underwent microvascular decompression for trigeminal neuralgia. Neurosurgery 2011; 69:15-25; discussion 26 CrossRef Medline

15. Becker M, Kohler R, Vargas MI, et al. Pathology of the trigeminal nerve. Neuroimaging Clin N Am 2008;18:283-307, x CrossRef Medline

16. Borges A, Casselman J. Imaging the trigeminal nerve. Eur J Radiol 2010;74:323-40 CrossRef Medline

17. Leal PR, Hermier M, Froment JC, et al. Preoperative demonstration of the neurovascular compression characteristics with special emphasis on the degree of compression, using high-resolution magnetic resonance imaging: a prospective study, with comparison to surgical findings, in 100 consecutive patients who underwent microvascular decompression for trigeminal neuralgia. Acta Neurochir (Wien) 2010;152:817-25 CrossRef Medline

18. Leal PR, Froment JC, Sindou M. Predictive value of MRI for detecting and characterizing vascular compression in cranial nerve hy- peractivity syndromes (trigeminal and facial nerves) [in French]. Neurochirurgie 2009;55:174-80 CrossRef Medline

19. Naraghi R, Tanrikulu L, Troescher-Weber R, et al. Classification of neurovascular compression in typical hemifacial spasm: threedimensional visualization of the facial and the vestibulocochlear nerves. J Neurosurg 2007;107:1154-63 CrossRef Medline

20. Herweh C, Kress B, Rasche D, et al. Loss of anisotropy in trigeminal neuralgia revealed by diffusion tensor imaging. Neurology 2007;68: 776-78 CrossRef Medline

21. Lutz J, Linn J, Mehrkens JH, et al. Trigeminal neuralgia due to neurovascular compression: high-spatial-resolution diffusion-tensor imaging reveals microstructural neural changes. Radiology 2011; 258:524-30 CrossRef Medline

22. Yildiz E, Yolcu S. Volume of the cisternal portion of the trigeminal nerve: a study with 3.0-Tesla constructive-interference-in-steadystate imaging of healthy subjects. J Neurological Sci (Turkish) 2015;32:106-14

23. Love $S$, Coakham HB. Trigeminal neuralgia: pathology and pathogenesis. Brain 2001;124:2347-60 CrossRef Medline

24. Katusic S, Beard CM, Bergstralh E, et al. Incidence and clinical features of trigeminal neuralgia, Rochester, Minnesota, 1945-1984. Ann Neurol 1990;27:89-95 CrossRef Medline

25. Manzoni GC, Torelli P. Epidemiology of typical and atypical craniofacial neuralgias. Neurol Sci 2005;26(suppl 2):s65-67 CrossRef Medline

26. Maarbjerg S, Gozalov A, Olesen J, et al. Trigeminal neuralgia: a prospective systematic study of clinical characteristics in 158 patients. Headache 2014;54:1574-82 CrossRef Medline

27. de Bondt BJ, Stokroos R, Casselman J. Persistent trigeminal artery associated with trigeminal neuralgia: hypothesis of neurovascular compression. Neuroradiology 2007;49:23-26 CrossRef Medline

28. García-Pastor C, López-González F, Revuelta R, et al. Trigeminal neuralgia secondary to arteriovenous malformations of the posterior fossa. Surg Neurol 2006;66:207-11; discussion 211 CrossRef Medline

29. Park SH, Hwang SK, Lee SH, et al. Nerve atrophy and a small cerebellopontine angle cistern in patients with trigeminal neuralgia. J Neurosurg 2009;110:633-37 CrossRef Medline

30. Brisman R, Khandji AG, Mooij RB. Trigeminal nerve-blood vessel relationship as revealed by high-resolution magnetic resonance imaging and its effect on pain relief after gamma knife radiosurgery for trigeminal neuralgia. Neurosurgery 2002;50:1261-66, discussion 1266-67 Medline

31. Devor M, Govrin-Lippmann R, Rappaport ZH. Mechanism of trigeminal neuralgia: an ultrastructural analysis of trigeminal root specimens obtained during microvascular decompression surgery. J Neurosurg 2002;96:532-43 CrossRef Medline

32. Suzuki M, Yoshino N, Shimada M, et al. Trigeminal neuralgia: differences in magnetic resonance imaging characteristics of neurovascular compression between symptomatic and asymptomatic nerves. Oral Surg Oral Med Oral Pathol Oral Radiol 2015;119:113-18 CrossRef Medline

33. Sindou M, Leston J, Howeidy T, et al. Micro-vascular decompression for primary trigeminal neuralgia (typical or atypical): longterm effectiveness on pain-prospective study with survival analysis in a consecutive series of 362 patients. Acta Neurochir (Wien) 2006;148:1235-45; discussion 1245 CrossRef Medline

34. Oesman C, Mooij JJ. Long-term follow-up of microvascular decompression for trigeminal neuralgia. Skull Base 2011;21:313-22 CrossRef Medline

35. Chun-Cheng Q, Qing-Shi Z, Ji-Qing Z, et al. A single-blinded pilot study assessing neurovascular contact by using high-resolution MR imaging in patients with trigeminal neuralgia. Eur J Radiol 2009;69: 459-63 CrossRef Medline

36. Antonini G, Di Pasquale A, Cruccu G, et al. Magnetic resonance imaging contribution for diagnosing symptomatic neurovascular contact in classical trigeminal neuralgia: a blinded case-control study and meta-analysis. Pain 2014;155:1464-71 CrossRef Medline 
37. Tash RR, Sze G, Leslie DR. Trigeminal neuralgia: MR imaging features. Radiology 1989;172:767-70 CrossRef Medline

38. Bederson JB, Wilson CB. Evaluation of microvascular decompression and partial sensory rhizotomy in 252 cases of trigeminal neuralgia. J Neurosurg 1989;71:359-67 CrossRef Medline

39. Erbay SH, Bhadelia RA, O'Callaghan M, et al. Nerve atrophy in severe trigeminal neuralgia: noninvasive confirmation at MR imaging-initial experience. Radiology 2006;238:689-92 CrossRef Medline

40. Horínek D, Brezová V, Nimsky C, et al. The MRI volumetry of the posterior fossa and its substructures in trigeminal neuralgia: a validated study. Acta Neurochir (Wien) 2009;151:669-75 CrossRef Medline

41. Kress B, Schindler M, Rasche D, et al. MRI volumetry for the preoperative diagnosis of trigeminal neuralgia. Eur Radiol 2005;15: 1344-48 CrossRef Medline

42. Liu Y, Li J, Butzkueven $\mathrm{H}$, et al. Microstructural abnormalities in the trigeminal nerves of patients with trigeminal neuralgia revealed by multiple diffusion metrics. Eur J Radiol 2013;82:783-86 CrossRef Medline

43. Leal PR, Roch JA, Hermier M, et al. Structural abnormalities of the trigeminal root revealed by diffusion tensor imaging in patients with trigeminal neuralgia caused by neurovascular compression: a prospective, double-blind, controlled study. Pain 2011;152: 2357-64 CrossRef Medline

44. Wilcox SL, Gustin SM, Eykman EN, et al. Trigeminal nerve anatomy in neuropathic and non-neuropathic orofacial pain patients. J Pain 2013;14:865-72 CrossRef Medline

45. Prieto R, Pascual JM, Yus M, et al. Trigeminal neuralgia: assessment of neurovascular decompression by 3D fast imaging employing steady-state acquisition and 3D time of flight multiple overlapping thin slab acquisition magnetic resonance imaging. Surg Neurol Int 2012;3:50 CrossRef Medline

46. Tomii M, Onoue $\mathrm{H}$, Yasue M, et al. Microscopic measurement of the facial nerve root exit zone from central glial myelin to peripheral Schwann cell myelin. J Neurosurg 2003;99:121-24 CrossRef Medline

47. Skinner HA. The origin of acoustic nerve tumours. Br J Surg 1929; 16:440-63 CrossRef

48. Kong DS, Park K. Hemifacial spasm: a neurosurgical perspective. $J$ Korean Neurosurg Soc 2007;42:355-62 CrossRef Medline
49. Auger RG, Whisnant JP. Hemifacial spasm in Rochester and Olmsted County, Minnesota, 1960 to 1984. Arch Neurol 1990;47: 1233-34 CrossRef Medline

50. Sindou MP. Microvascular decompression for primary hemifacial spasm. Importance of intraoperative neurophysiological monitoring. Acta Neurochir (Wien) 2005;147:1019-26; discussion 1026 CrossRef Medline

51. Sindou M, Keravel Y. Neurosurgical treatment of primary hemifacial spasm with microvascular decompression [in French]. Neurochirurgie 2009;55:236-47 CrossRef Medline

52. Dou NN, Zhong J, Zhou QM, et al. The mechanism of hemifacial spasm: a new understanding of the offending artery. Neurol Res 2015;37:184-88 CrossRef Medline

53. Guclu B, Sindou M, Meyronet D, et al. Anatomical study of the central myelin portion and transitional zone of the vestibulocochlear nerve. Acta Neurochir (Wien) 2012;154:2277-83; discussion 2283 CrossRef Medline

54. Pirsig W, Eckermeier L, Mueller D. As to the origin of vestibular schwannomas. In: House WF, Luetje CM, eds. Acoustic Tumors. Vol 1. Baltimore: University Park Press; 1979:52-55

55. Ryu H, Yamamoto S, Sugiyama K, et al. Neurovascular compression syndrome of the eighth cranial nerve: can the site of compression explain the symptoms? Acta Neurochir (Wien) 1999;141:495-501 CrossRef Medline

56. Best C, Gawehn J, Krämer HH, et al. MRI and neurophysiology in vestibular paroxysmia: contradiction and correlation. J Neurol Neurosurg Psychiatry 2013;84:1349-56 CrossRef Medline

57. Laha RK, Jannetta PJ. Glossopharyngeal neuralgia. J Neurosurg 1977; 47:316-20 CrossRef Medline

58. Spurling RG, Grantham EG. Glossopharyngeal neuralgia. South Med J 1942;35:509-12

59. Sindou M, Keravel Y. Neurosurgical treatment of vago-glossopharyngeal neuralgia [in French]. Neurochirurgie 2009;55:231-35 CrossRef Medline

60. Alafaci C, Granata F, Cutugno M, et al. Glossopharyngeal neuralgia caused by a complex neurovascular conflict: case report and review of the literature. Surg Neurol Int 2015;6:19 CrossRef Medline

61. Hiwatashi A, Matsushima T, Yoshiura T, et al. MRI of glossopharyngeal neuralgia caused by neurovascular compression. AJR Am J Roentgenol 2008;191:578-81 CrossRef Medline 